\title{
Clinical Reasoning: A 2-Day-Old Boy With Sudden Cardiac Arrest and Encephalopathy
}

Brandon B. Holmes, MD, PhD, Jeffrey B. Russ, MD, PhD, Yvonne W. Wu, MD, MPH, Renata C. Gallagher, MD, PhD, and Dawn Gano, MD, MAS

Neurology ${ }^{\circledR}$ 2021;97:e1743-e1746. doi:10.1212/WNL.0000000000012408

\section{Correspondence}

Dr. Holmes

brandon.holmes2@ucsf.edu

\section{Section 1}

A 36-week, 5-day-old boy was born through uncomplicated vaginal delivery to a healthy, 36year-old G7P4 mother. His resuscitation included tactile warmth, drying, and stimulation, and his Apgar scores were 8 and 9 at 1 and 5 minutes, respectively. He was small for gestational age with a birth weight of $2100 \mathrm{~g}$ ( 0.16 percentile). His course was unremarkable with normal behavior and breastfeeding for approximately 40 hours of life.

On day 2 of life, he became acutely bradycardic to the 60s, apneic, and then pulseless. Resuscitation was performed for 60 minutes with chest compressions, defibrillator shocks, and administration of epinephrine. Notable laboratory test results included a potassium level of 6.8 $\mathrm{mmol} / \mathrm{L}$, a WBC count of $19.7 \times 10^{9} / \mathrm{L}$, an INR of 2.6 , a lactate of $5.2 \mathrm{mmol} / \mathrm{L}$, and a glucose level of $9 \mathrm{mg} / \mathrm{dL}$. After successful resuscitation and administration of a dextrose bolus, his glucose level improved to $245 \mathrm{mg} / \mathrm{dL}$ but then rapidly decreased again to $75 \mathrm{mg} / \mathrm{dL}$. He was started on a continuous dextrose infusion, and his subsequent glucose levels normalized.

The patient was intubated and transported to our institution's intensive care nursery for further evaluation. Neurologic examination on admission, while receiving $0.01 \mathrm{mg} / \mathrm{kg} / \mathrm{h}$ morphine, was notable for somnolence, absent behavioral response to light, diffuse hypotonia, absent spontaneous movements, slight reactive movements with stimulation, hyperreflexia in his upper extremities, and weak suck and Moro reflexes.

\section{Questions for Consideration:}

1. What is the differential diagnosis for sudden decompensation in a previously healthy neonate?

2. What diagnostic evaluations should be included to distinguish these possibilities?

3. What empiric therapies would you initiate for this patient?

\section{GO TO SECTION 2}




\section{Section 2}

Our differential diagnosis included infectious, cardiac, neurologic, and metabolic causes for sudden neonatal decompensation.

From an infectious standpoint, he remained afebrile, his peak WBC count was $21.5 \times 10^{9} / \mathrm{L}$, and his blood cultures were negative. A lumbar puncture was deferred given a low suspicion for meningitis.

Cardiac workup included ECGs demonstrating normal sinus rhythm. An echocardiogram showed normal cardiac anatomy with a possible ventricular septal defect and an elevated right ventricular pressure. Troponin was elevated at $0.13 \mu \mathrm{g} / \mathrm{L}$, and B-type natriuretic peptide was elevated at $1,840 \mathrm{pg} / \mathrm{mL}$. Together, these data supported a cardiomyopathy but whether cardiomyopathy was the primary cause of, or a secondary result of, the cardiac arrest was unclear.

Neurologically, his EEG showed nonspecific findings of mild excessive discontinuity and moderate voltage attenuation (figure $1, A$ and B), which normalized over 24 hours (eFigure $1 \mathrm{~A}$ and $\mathrm{B}$ available from Dryad: doi.org/10.7272/Q6JQ0Z8F); there were no epileptiform discharges or seizures. At day 5, his encephalopathy improved and he had only mild hypotonia. A brain MRI with spectroscopy performed on day 6 was unremarkable (figure $1, \mathrm{C}-\mathrm{F}$ ) and without evidence of hypoxic-ischemic injury.

The patient's small size for gestational age, severe hypoglycemia, cardiomyopathy, and sudden decompensation in an otherwise healthy infant led us to consider metabolic disorders as a unifying diagnosis; however, initial metabolic studies were unrevealing. His liver function tests and ammonia were normal, and his elevated BUN of $31 \mathrm{mg} / \mathrm{dL}$ and lactate of $5.2 \mathrm{mmol} / \mathrm{L}$ were more likely a consequence of his acute cardiac arrest. Thus, more targeted metabolic testing was warranted.

\section{Questions for Consideration:}

1. Is there a unifying diagnosis or category of diagnoses you would consider?

2. Are there additional metabolic studies you would send at this time?

3. Given the results of his neurologic workup, what can you infer about the severity of his anoxic brain injury?

Figure 1 The Patient's EEG, Radiologic, and Genetic Data
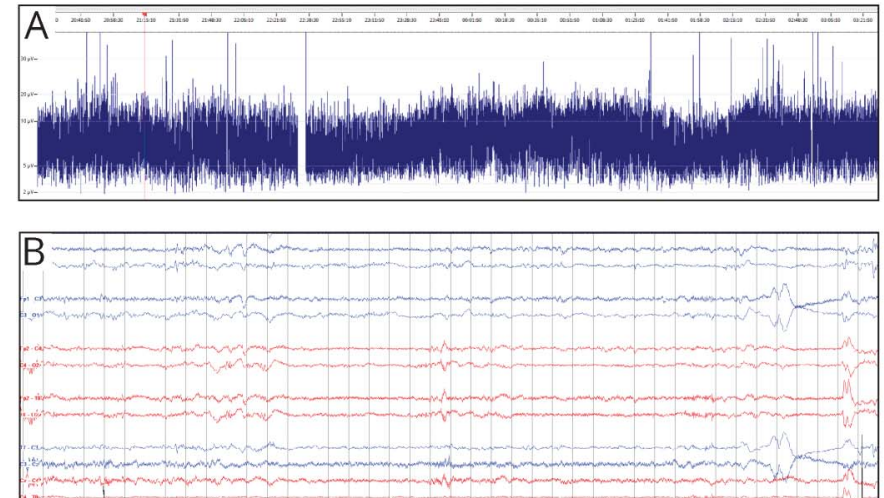

G

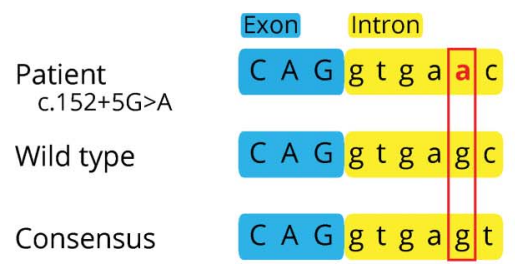

H
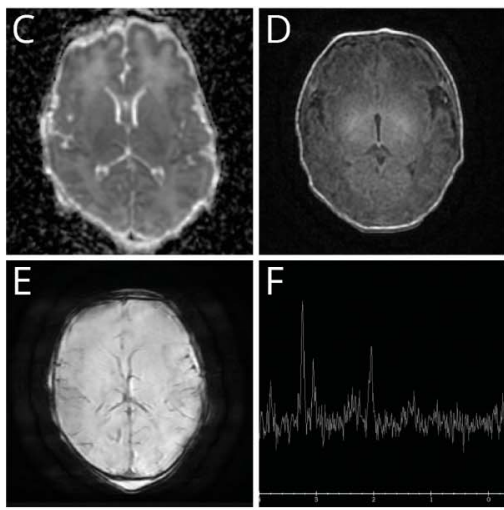

\begin{tabular}{|l|c|c|c|}
\hline & MaxEntScan & Hbond & NNSplice \\
\hline Patient & 5.56 & 12.40 & 0.59 \\
\hline Wild type & 9.60 & 17.40 & 0.99 \\
\hline Consensus & 10.67 & 19.90 & 1 \\
\hline
\end{tabular}

(A) Amplitude-integrated EEG demonstrated a discontinuous background with attenuated voltages but without seizures. (B) Full bipolar montage EEG demonstrating discontinuity with interburst intervals of about 8 seconds, but no epileptiform discharges or seizures. EEG was performed while the patient was receiving $0.01 \mathrm{mg} / \mathrm{kg} / \mathrm{h}$ morphine. (C-F) Axial sections from the patient's brain MRI demonstrating a normal ADC map (C) without evidence of acute injury, a normal T1-weighted sequence (D) without evidence of injury or structural malformations, and a normal susceptibility-weighted sequence (E) without evidence of intracranial hemorrhage. (F) The patient's MR spectroscopy sampled from the basal ganglia demonstrates no abnormal peaks to suggest acute injury or metabolic derangement. (G) Schematic diagram demonstrating the sequence variation of our patient in comparison with wild-type and consensus splice site sequences. The $152+5 \mathrm{G}>\mathrm{A}$ variant is contained within the $5^{\prime}$ splice site consensus sequence encoding a $\mathrm{G} \rightarrow \mathrm{A}$ transversion at nucleotide 5 from the intron start site (bold red font). The wild-type sequence is the most frequent allele found in healthy populations. The consensus sequence is a strong variant of the canonical sequence MAG |GURAGU, where M is adenine or cytosine and R is a purine. (H) Summary data of in silico models used to predict the strength of the patient's splice site: MaxEntScan uses the principle of maximum entropy to score the strength of a splice site. HBond calculates the number of hydrogen bonds formed between the splice site and the U1 snRNA. NNSplice is a neural network trained on established consensus splice sites. In all cases, a higher score indicates a stronger potential splice site, and in all cases, the patient's genetic variant scored substantially lower than the wild-type or consensus sequences. These models have been previously validated as robust predictors of cryptic splicing ${ }^{12}$ and are freely available to the public. 


\section{Section 3}

The patient rapidly improved as evidenced by his 24-hour follow-up examination, EEG, and brain MRI. Taken together, this data suggest that he did not suffer significant cerebral hypoperfusion and imply that he was likely not pulseless for the full 60-minute code.

To expand his metabolic evaluation, further screening studies were ordered. His plasma amino acid analysis was unremarkable, but his urine organic acid analysis identified elevated lactate and medium- and long-chain fatty acids. His plasma acylcarnitine profile and the California state newborn screen revealed an elevation of multiple long-chain acylcarnitine species, including dramatic elevations of C16 and C18:1 acylcarnitines. This pattern is characteristic of 2 long-chain fatty acid oxidation disorders — carnitine palmitoyltransferase 2 (CPT2) deficiency and carnitine-acylcarnitine translocase (CACT) deficiency, which cannot be distinguished biochemically. For genetic confirmation, an InVitae Fatty Acid Oxidation Defects Panel was sent, which identified 2 genetic variants: (1) heterozygosity of c.625G $>$ A (p.Gly209Ser) in ACADS, which is a benign and common variant, ${ }^{1,2}$ and (2) homozygosity of c. $152+5 \mathrm{G}>\mathrm{A}$ (intronic) in CPT2, which is a variant of uncertain significance and was presumed to be pathogenic (figure $1 G$ ).

Given the strong clinical, biochemical, and genetic evidence of CPT2 deficiency, the infant was initiated on a long-chain fatrestricted diet, supplemented with levocarnitine and mediumchain triglyceride (MCT) oil, and started on triheptanoin, a newly FDA-approved medium-chain triglyceride.,

\section{Discussion}

CPT2 deficiency is an autosomal recessive disorder of fatty acid metabolism characterized by recurrent attacks of myalgias and myoglobinuria. ${ }^{5}$ The disease manifests as 3 distinct phenotypes: (1) a mild myopathic form that starts in childhood or adulthood, (2) a severe multisystem infantile form, and (3) a lethal neonatal form. ${ }^{5}$ In the mild myopathic form, patients may present in the second or third decade of life with exercise-induced weakness, myalgias, and rhabdomyolysis, the latter of which can cause acute renal failure. ${ }^{5}$ Conversely, the lethal neonatal form is exceedingly rare, and affected individuals present with nonketotic hypoglycemia, hypotonia, cardiomyopathy, cardiac arrhythmias, and seizures. ${ }^{6}$ Patients often die within the first months of life because of cardiomyopathy or hypoglycemia-associated cardiac arrhythmias or seizures. ${ }^{6,7}$ Our patient suffered a life-threatening cardiac arrest, which was attributed to a cardiac arrhythmia secondary to severe hypoglycemia and hyperkalemia.

Biochemically, CPT2 deficiency leads to tissue energy failure through aberrant shuttling of acylcarnitines to the betaoxidation pathway. The carnitine shuttle is a cellular pathway that delivers long-chain fatty acids from the cytosol to the mitochondria. Long-chain fatty acids are transported as acylcarnitines through the sequential actions of acyl-CoA synthetase, carnitine palmitoyltransferase I (CPT1), and carnitine-acylcarnitine translocase (CACT). Once in the mitochondria, these long-chain fatty acids are reconverted into their original acyl-CoAs by carnitine palmitoyltransferase II (CPT2) to supply the precursors for beta-oxidation. Disruption of this pathway leads to failed production of acetyl-CoA for ketone generation as well as $\mathrm{FADH}_{2}$ and $\mathrm{NADH}^{+}$that are required for oxidative phosphorylation. ${ }^{8}$

Diagnostically, CPT2 deficiency is inferred through newborn screen blood spots or plasma acylcarnitine profiles using mass spectrometry. This test shows the characteristic elevation of long-chain acylcarnitines, especially C16:0 and C18:1, and a concomitant decrease in $\mathrm{C} 2 .{ }^{5}$ Our patient had a 55.4-fold and 22.1-fold increase in C16:0 and C18:1, respectively, and a 3.5fold decrease in C2 (eTable available from Dryad: doi.org/10. 7272/Q6JQ0Z8F). CPT2 deficiency results in an identical acylcarnitine pattern to CACT deficiency, and therefore, genetic analysis is required to differentiate these 2 diseases.

The InVitae Fatty Acid Oxidation Defects Panel found that our patient harbors a novel and previously unreported homozygous variant within intron 1 of CPT2 (figure 1G). To predict the effects of our patient's variant on gene splicing, we used 3 in silico modeling algorithms that assess the strength of the modified splice site. ${ }^{9-11}$ All 3 models predicted weak splice site activity relative to the wild-type sequence (figure $1 \mathrm{H}$ ). The functional consequences of such variants are disruption of the native U1 snRNP binding to the consensus splice site, which results in the unmasking of alternative splice sites in other regions of the transcript. This process, referred to as cryptic splicing, leads to the aberrant production of nonphysiologic mRNA splice variants. ${ }^{12,13}$ Taken together, this supports a pathologic role for this patient's homozygous $152+5 \mathrm{G}>\mathrm{A}$ variant in $C P T 2$, likely through the production of a cryptic splice site. Functional validation at the transcript and protein level is needed to validate this hypothesis.

Notably, only 1 prior report has identified an association between consensus splice sequence variants and neonatal CPT2 deficiency. ${ }^{14}$ In this cohort, all affected individuals were compound heterozygotes for an indel mutation and a 3 ' splice site mutation. Thus, we report a novel case of CPT2 deficiency due to homozygosity of a splice site variant alone.

Unfortunately, treatment options for CPT2 deficiency remain limited. Therapies focus on avoidance of metabolic decompensation by avoiding prolonged fasting, restricting longchain fatty acid intake, supplementing medium-chain fatty acids and carnitine, and encouraging frequent carbohydrate-rich meals. In 2020, the FDA approved the use of triheptanoin, a 7carbon medium-chain triglyceride, for the treatment of longchain fatty acid oxidation disorders. Triheptanoin is metabolized independently of the cellular pathway for long-chain fatty acid oxidation, and clinical trials demonstrate that treated patients are less likely to develop hypoglycemia, cardiomyopathy, 
rhabdomyolysis, and hepatomegaly. ${ }^{2,3}$ However, this drug has not been tested in the neonatal form of CPT2 deficiency.

Understanding the molecular basis of CPT2 deficiency is crucial to inspire future therapeutic discoveries. It is intriguing to speculate that splice site-mediated CPT2 deficiency could be treated with splice-modulating antisense oligonucleotides as has been done in spinal muscular atrophy and Duchenne muscular dystrophy. ${ }^{15}$ Given the ever-increasing use of newborn screening and genetic profiling, it may indeed be possible to engineer patient-specific targeted therapies for early intervention of these devastating metabolic disorders.

\section{Acknowledgment}

Data Availability: Deidentified patient information from this case will be made available to other clinicians and researchers on written request to the corresponding author.

The authors thank Anne Mardy, MD, for her contribution to this patient's evaluation and care.

\section{Study Funding}

No targeted funding reported.

\section{Disclosure}

Jeffrey B. Russ is a member of the Neurology Resident \& Fellow Section Editorial Team. There are no other financial disclosures or conflicts of interest to report. Go to Neurology. org/ $\mathrm{N}$ for full disclosures.

Appendix Authors

\begin{tabular}{|c|c|c|c|}
\hline Name & Location & Role & Contribution \\
\hline $\begin{array}{l}\text { Brandon } \\
\text { Holmes, } \\
\text { MD, PhD }\end{array}$ & $\begin{array}{l}\text { University of } \\
\text { California San } \\
\text { Francisco, CA }\end{array}$ & Author & $\begin{array}{l}\text { Designed and conceptualized } \\
\text { the study, participated in } \\
\text { patient care, analyzed data, and } \\
\text { drafted and revised the } \\
\text { manuscript }\end{array}$ \\
\hline $\begin{array}{l}\text { Jeffrey } \\
\text { Russ, MD, } \\
\text { PhD }\end{array}$ & $\begin{array}{l}\text { University of } \\
\text { California San } \\
\text { Francisco, CA }\end{array}$ & Author & $\begin{array}{l}\text { Designed and conceptualized } \\
\text { the study, participated in } \\
\text { patient care, analyzed data, and } \\
\text { drafted and revised the } \\
\text { manuscript }\end{array}$ \\
\hline
\end{tabular}

Appendix (continued)

\begin{tabular}{llll}
\hline Name & Location & Role & Contribution \\
\hline $\begin{array}{l}\text { Yvonne Wu, } \\
\text { MD, MPH } \\
\text { California San } \\
\text { Francisco, CA }\end{array}$ & Author & $\begin{array}{l}\text { Designed and conceptualized } \\
\text { the study, participated in } \\
\text { patient care, analyzed data, and } \\
\text { revised the manuscript }\end{array}$ \\
$\begin{array}{l}\text { Renata } \\
\text { Gallagher, } \\
\text { MD, PhD }\end{array}$ & $\begin{array}{l}\text { University of } \\
\text { California San }\end{array}$ & Author & $\begin{array}{l}\text { Participated in patient care, } \\
\text { analyzed data, and revised the } \\
\text { manuscript }\end{array}$ \\
$\begin{array}{l}\text { Dawn Gano, } \\
\text { MD, MAS }\end{array}$ & $\begin{array}{l}\text { University of } \\
\text { California San } \\
\text { Francisco, CA }\end{array}$ & Author & $\begin{array}{l}\text { Designed and conceptualized } \\
\text { the study, participated in } \\
\text { patient care, analyzed data, and } \\
\text { revised the manuscript }\end{array}$ \\
& & &
\end{tabular}

\section{References}

1. Gallant NM, Leydiker K, Tang H, et al. Biochemical, molecular, and clinical characteristics of children with short chain acyl-CoA dehydrogenase deficiency detected by newborn screening in California. Mol Genet Metab. 2012;106(1):55-61.

2. Pena L, Angle B, Burton B, Charrow J. Follow-up of patients with short-chain acylCoA dehydrogenase and isobutyryl-CoA dehydrogenase deficiencies identified through newborn screening: one center's experience. Genet Med. 2012;14(3) 342-347.

3. Roe CR, Yang B-Z, Brunengraber H, Roe DS, Wallace M, Garritson BK. Carnitine palmitoyltransferase II deficiency: successful anaplerotic diet therapy. Neurology. $2008 ; 71(4): 260-264$

4. Gillingham MB, Heitner SB, Martin J, et al. Triheptanoin versus trioctanoin for longchain fatty acid oxidation disorders: a double blinded, randomized controlled trial J Inherit Metab Dis. 2017;40(6):831-843.

5. Deschauer M, Wieser T, Zierz S. Muscle carnitine palmitoyltransferase II deficiency: clinical and molecular genetic features and diagnostic aspects. Arch Neurol. 2005; 62(1):37.

6. Lehmann D, Motlagh L, Robaa D, Zierz S. Muscle carnitine palmitoyltransferase II deficiency: a review of enzymatic controversy and clinical features. Int J Mol Sci. 2017; 18(1):82.

7. Reno CM, Skinner A, Bayles J, Chen YS, Daphna-Iken D, Fisher SJ. Severe hypoglycemia-induced sudden death is mediated by both cardiac arrhythmias and seizures. Am J Physiology-Endocrinology Metab. 2018;315(2):E240-E249.

8. Merritt JL, Norris M, Kanungo S. Fatty acid oxidation disorders. Ann Transl Med. 2018;6(24):473.

9. Yeo G, Burge CB. Maximum entropy modeling of short sequence motifs with applications to RNA splicing signals. J Comput Biol. 2004;11(2-3):377-394.

10. Freund M, Asang C, Kammler S, et al. A novel approach to describe a U1 snRNA binding site. Nucleic Acids Res. 2003;31(23):6963-6975.

11. Reese MG, Eeckman FH, Kulp D, Haussler D. Improved splice site detection in Genie. J Comput Biol. 1997;4(3):311-323.

12. Buratti E, Chivers M, Kralovicova J, et al. Aberrant 5' splice sites in human disease genes: mutation pattern, nucleotide structure and comparison of computational tools that predict their utilization. Nucleic Acids Res. 2007;35(13):4250-4263.

13. Anna A, Monika G. Splicing mutations in human genetic disorders: examples, detection, and confirmation. J Appl Genet. 2018;59(3):253-268.

14. Smeets RJP, Smeitink JAM, Semmekrot BA, Scholte HR, Wanders RJA, van den Heuvel LPWJ. A novel splice site mutation in neonatal carnitine palmitoyl transferase II deficiency. J Hum Genet. 2003;48(1):8-13.

15. Sazani P, Kole R. Therapeutic potential of antisense oligonucleotides as modulators of alternative splicing. J Clin Invest. 2003;112(4):481-486. 


\section{Neurology}

\section{Clinical Reasoning: A 2-Day-Old Boy With Sudden Cardiac Arrest and Encephalopathy}

Brandon B. Holmes, Jeffrey B. Russ, Yvonne W. Wu, et al.

Neurology 2021;97;e1743-e1746 Published Online before print June 22, 2021

DOI 10.1212/WNL.0000000000012408

This information is current as of June 22, 2021

\section{Updated Information \& Services}

References

Subspecialty Collections

Permissions \& Licensing

Reprints including high resolution figures, can be found at: http://n.neurology.org/content/97/17/e1743.full

This article cites 15 articles, 1 of which you can access for free at: http://n.neurology.org/content/97/17/e1743.full\#ref-list-1

This article, along with others on similar topics, appears in the following collection(s):

All Clinical Neurology

http://n.neurology.org/cgi/collection/all_clinical_neurology

All Genetics

http://n.neurology.org/cgi/collection/all_genetics

Hypoglycemia

http://n.neurology.org/cgi/collection/hypoglycemia

Metabolic disease (inherited)

http://n.neurology.org/cgi/collection/metabolic_disease_inherited

Neonatal

http://n.neurology.org/cgi/collection/neonatal

Information about reproducing this article in parts (figures,tables) or in its entirety can be found online at:

http://www.neurology.org/about/about_the_journal\#permissions

Information about ordering reprints can be found online:

http://n.neurology.org/subscribers/advertise

Neurology ${ }^{\circledR}$ is the official journal of the American Academy of Neurology. Published continuously since 1951, it is now a weekly with 48 issues per year. Copyright (C 2021 American Academy of Neurology. All rights reserved. Print ISSN: 0028-3878. Online ISSN: 1526-632X.

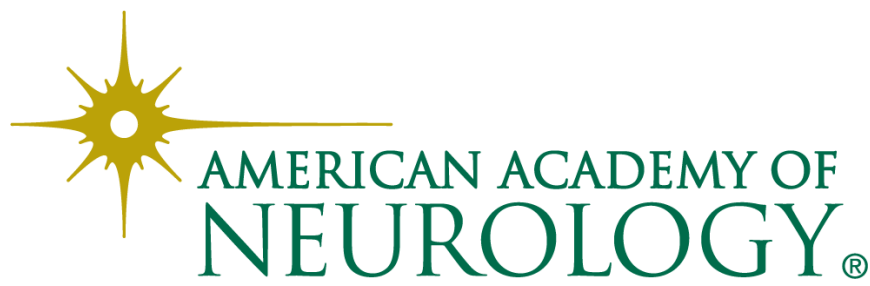

